Abstracta Iranica Abstracta Iranica

Revue bibliographique pour le domaine irano-aryen

Volume 26 | 2005

Comptes rendus des publications de 2003

«Quindici ghazal persiani del poeta sikh Divān Singh Khaliq Lāhuri ». Annali di Ca'Foscari, XLI, 3, (2002), pp. 89-121, (Serie orientale 33).

Justine Landau

\title{
CpenEdition
}

1 Journals

Édition électronique

URL : http://journals.openedition.org/abstractairanica/2033

DOI : 10.4000/abstractairanica.2033

ISSN : 1961-960X

Éditeur :

CNRS (UMR 7528 Mondes iraniens et indiens), Éditions de l'IFRI

Édition imprimée

Date de publication : 15 mai 2005

ISSN : 0240-8910

Référence électronique

Justine Landau, « «Quindici ghazal persiani del poeta sikh Divān Singh Khaliq Lāhuri ». Annali di Ca'Foscari, XLI, 3, (2002), pp. 89-121, (Serie orientale 33). », Abstracta Iranica [En ligne], Volume 26 | 2005, document 378, mis en ligne le 07 décembre 2005, consulté le 25 septembre 2020. URL : http:// journals.openedition.org/abstractairanica/2033; DOI : https://doi.org/10.4000/abstractairanica.2033

Ce document a été généré automatiquement le 25 septembre 2020.

Tous droits réservés 


\section{«Quindici ghazal persiani del poeta sikh Divān Singh Khaliq Lāhuri ». Annali di Ca'Foscari, XLI, 3, (2002), pp. 89-121, (Serie orientale 33).}

Justine Landau

De la constellation peu connue des poètes sikhs et hindous d'expression persane qui vécurent et composèrent en Inde au $12^{\mathrm{e}} / 18^{\mathrm{e}} \mathrm{s}$., l'A. choisit de présenter l'œuvre du poète sikh Dīvān Singh Hāaliq Lāhurī, dont le recueil a récemment fait l'objet d'une édition critique au Pakistan, à partir du manuscrit unique de son œuvre, copié au Kashmir en 1199/1785. En l'absence d'informations biographiques externes, on ne sait pas grand-chose de cet auteur, originaire du Panjab et secrétaire de métier (munšī), qui vécut un temps au Kashmir. L'exposé s'articule en deux temps. Avant de proposer une sélection de 15 gazal, scandés, translittérés et traduits en italien, l'A. s'attache à éclairer la production poétique de Hāaliq, exemplaire de son milieu d'exercice, à partir des personnages, cités dans son œuvre, qu'il a pu fréquenter, et de ses options religieuses. La lecture du recueil est l'occasion pour l'A. de mettre en perspective l'emploi du persan et de la forme poétique du gazal par des auteurs non musulmans. L'omniprésence de références à des motifs propres à la culture arabo-musulmane et iranienne témoigne d'une réelle islamisation culturelle ainsi que d'une persanisation linguistique et littéraire profonde de l'Inde moghole. Les sikhs dans leur ensemble ont d'ailleurs compté parmi les non-musulmans les plus actifs à promouvoir le persan littéraire dans le monde indien. Quant à la poésie de Hुāliq, à dominante mystique, elle se caractérise par la synthèse d'éléments caractéristiques du mysticisme musulman à d'autres, propres aux religions indiennes. Ses textes entretiennent au demeurant une relation d'émulation avec un intertexte très majoritairement indien, dans la tradition du jawāb. L'échantillon de gazalīyāt proposés répond à des critères de représentativité stylistique et de contenu, qui mettent en évidence le rattachement du poète au «style 
indien ». Ouvrant des perspectives novatrices, cette contribution éclaire avec érudition un domaine littéraire encore très peu étudié.

INDEX

Thèmes: 11.1.1. Littérature persane classique

Mots-clés : Poésie, poètes Sikhs, poètes hindou

Keywords : poésie persane, Poetry, Persian poetry, gazal, Sikh poets, Hindu poets

\section{AUTEURS}

JUSTINE LANDAU

Paris 